\title{
La debilidad de las mujeres
}

\section{The Weakness of Women}

\author{
John B. Watson \\ Traducción: Carlos Silva
}

(Publicación original: Watson, John. B. (1927). The Weakness of Women. TheNation, 125, 3235, 9-10).

\begin{abstract}
¿Cuánta verdad están diciendo las mujeres en sus biografías? En el mejor de los casos, las biografías revelan, principalmente, superficialidades. Es curioso que los seres humanos sepan tan poco de sí mismos. Casi nunca nos destrozamos a nosotros mismos para ver cómo las partes trabajan juntas. Es mucho más fácil destrozar a los demás. Desde la infancia aprendemos a culpar por nuestros fracasos a los padres, el hogar, los asociados, las condiciones económicas. Si logramos superarlas debe ser por alguna virtud innata, instintiva, que no será abatida por la adversidad. Todo esto sale en las biografías. Uno es golpeado por el fracaso de parte de casi todas las mujeres para rendir tributo a las adversidades del ambiente. A decir verdad, casi todas ellas se quejan de cuán magnificadas son sus penas. "Qué desperdicio", dice el conductista que cree que todos los individuos se hace, no nacen, "las tribulaciones y tristezas por las que pasaron estas mujeres fueron estímulos condicionantes que las forzaron a seguir un cierto camino." Probablemente, bajo lo que hubieran considerado un ambiente favorable la mayoría de ella hubiera alcanzado la edad de la gordura, los cuarenta, y de ella nunca se hubiera escuchado nada - hablo con cierta libertad, pues no conozco a ninguna de las damas.
\end{abstract}

La segunda cosa que impresiona de estas breves historias de vida es que todas las mujeres eran incansables —buscaban algo. ¿Por qué luchaban? ¿Por la felicidad? No; la felicidad, aparentemente, ha pasado de moda, no es un desideratum de la actualidad. Hoy le preguntamos a la gente cuántos coches tienen, si viven en la ciudad o en un pueblo, si juegan golf, tenis, o bridge, pero no les preguntamos sin son felices o no. Dudo de que los muchos niños y adultos de hoy entenderían lo que uno quiere decir si les preguntara, e insisto en que la felicidad puede definirse objetivamente en términos de conducta, que es una forma de conducta. Estas mujeres eran demasiado modernas para buscar la felicidad; ¿qué buscaban? Libertad. Cientos de mujeres con las que he hablado han buscado la libertad. He intentado descubrir no diplomáticamente sino conductualmente lo que querían decir. ¿Libertad es usar pantalones? ¿Es votar? ¿Detentar un cargo? ¿Hacer el trabajo de los hombres? ¿Alejar a los hombres de sus trabajos? ¿Tener el salario de los hombres? ¿Su demanda de esta cosa mística llamada libertad implica un resentimiento contra la crianza de sus hijos — un resentimiento contra el hecho de que la conducta sexual de los hombres es diferente a la de las mujeres (pero ya no tanto)? Raramente llegué a una respuesta razonable. Los analistas afirman que pueden llegar a la verdad de las mujeres a través del psicoanálisis. Yo no hago una afirmación así de temeraria. Puedo leer a las mujeres sólo después de hacer observaciones cuidadosas de su conducta durante largos periodos de tiempo. Luego pongo juntas dos y dos como cualquier otro científico. Cuando una mujer es una sufragista militante, ¿la probabilidad 
es, digamos, de cien a uno de que su vida sexual no está bien ajustada? El matrimonio como tal proporciona ajustes sólo en aproximadamente el 20 por ciento de los casos; así de pobre ha sido la enseñanza de hombres y mujeres sobre el sexo. Dentro de ese 20 por ciento, quienes encuentran un ajuste no son las mujeres militantes; no hallé mujeres gritando sus derechos sobre una carrera fantástica que los hombres - los brutos - les han robado. Trabajan como cualquier hombre (lo cual es lo mejor que pueda decirse del trabajo-. A menudo, silenciosamente hacen carrera. La mayoría de las mujeres terribles que uno debe conocer, mujeres con miradas y voces estridentes, mujeres que tienen que ser notadas, que te empujan con el hombro, que no pueden asumir la vida de una manera tranquila, pertenecen a este gran porcentaje de mujeres que nunca han hecho un ajuste sexual.

Las biografías como un todo confirman sorprendentemente la visión según la cual la militancia pasa tan pronto como la mujer, por el proceso de ensayo y error, encuentra su ajuste sexual. Entonces dejan de cazar la libertad, se pierden en su trabajo. Seguramente, la única libertad por la que vale la pena luchar sea la de estar completamente sumido en una actividad, sea esta actividad escribir una obra de teatro, lavar la ropa de un niño, o perderse en el vaivén de la pasión.

La gran debilidad de las mujeres (que buscan una carreta) es que nunca han sido entrenadas para trabajar como los hombres. Me refiero a entrenadas desde la infancia. Los hombre son criados en la tradición de que los hombres deben trabajar. Lo aprenden en la juventud en actividades con pandillas o, más tarde, en los deportes. Aprenden desde la niñez que deben mantener a sus familias y que para hacerlo deben tener una técnica para el trabajo — hábitos de trabajo- y que deben soportar la fatiga para endurecer sus músculos; deben aprender a hacer cualquier cosa lo suficientemente bien para poder competir. Se los entrena desde la infancia para adquirir hábitos de manipulación —las mujeres no. Ellas acostumbran a estar en el fino arte del bordado - sólo observen las muestras de las chicas de ocho a doce años. Se las entrenó para tejer, hilvanar, cocinar, y hacer sus propios vestidos. Luego la moda cambió - las mujeres tenían que ser damas- ornamentos bonitos. Su esfera estaba en casa. Ahora el cuadro está cambiando de nuevo. Las madres están comenzando a entrenar a sus hijas en hábitos de manipulación. Las costumbres de las mujeres han cambiando tan rápidamente que las tradiciones de trabajo no han tenido tiempo de absorberlo. Por lo tanto, pocas mujeres han logrado la grandeza.

Nunca he creído que hubiera dificultades insuperables que apartaran a las mujeres del éxito. Tienen fuerza suficiente para pintar, pero nunca ha habido una gran pintora. Tienen fuerza suficiente para tocar el violín, pero nunca ha habido una gran violinista. Tienen resistencia y fuerza suficientes para llegar a ser grandes científicas, pero se pueden contar con los dedos de una mano las científicas que han alcanzado la grandeza. Durante los últimos treinta años miles de mujeres han obtenido el título de Ph.D. y escasamente una docena ha salido al frente.

Al no haber sido entrenadas desde la infancia en la tradición del trabajo intensamente manipulativo, abandonan la carrera tan pronto como se sienten cómodas. El matrimonio es usualmente el punto clave que hace que se acuesten y descansen. Y cuando caen en eso, como el 80 por ciento lo hace, la intranquilidad surge de nuevo, pero ya es demasiado tarde para volver y retomar los hilos de la antigua carrera. La mayoría de las mujeres que tenían aspiraciones por una carrera han intentado comerse el pastel y a la vez conservarlo. Una carrera es un capataz celoso que acapara todo el tiempo.

El matrimonio como tal no debería ser una barrera para una carrera. Apartahoteles que pueden hallarse en cada ciudad donde una mujer pudiera hacer una carrera, han liberado liberado casi completamente a 
las mujeres casadas que no tienen hijos. Tener hijos es casi una barrera insuperable para una carrera. Criar a los niños y llevar un hogar es una profesión que no secunda a ninguna otra en demanda de una técnica.

La moral conductista - y debemos tener moral— es: A las mujeres no les gusta trabajar (a los hombres tampoco). No hay un "instinto" natural para el trabajo. Biológicamente hablando, el animal hambriento alcanza y coge un plátano; alcanza y abraza a su hembra (o viceversa); una vez que sacia su hambre, descansa y duerme. Los hábitos de trabajo son el resultado de la civilización y de la competencia. Si quieres que tus hijos tengan carreras, sean chicos o chicas, enséñales desde la infancia hábitos de manipulación, técnicas diestras, resistencia. El trabajo debe convertirse en una primera naturaleza segunda naturaleza no es suficiente. $Y$ junto con esto enséñales (o que les enseñen, si eres un puritano) qué esperar en la esfera del sexo.

\section{Formato de citación}

Watson, John B. (2009). La debilidad de las mujeres. Athenea Digital, 15, 203-205. Disponible en http://psicologiasocial.uab.es/athenea/index.php/atheneaDigital/article/view/4.

\begin{tabular}{l}
\hline Este texto está protegido por una licencia Creative Commons. \\
Usted es libre de copiar, distribuir y comunicar públicamente la obra bajo las siguientes condiciones: \\
Reconocimiento: Debe reconocer y citar al autor original. \\
No comercial. No puede utilizar esta obra para fines comerciales. \\
Sin obras derivadas. No se puede alterar, transformar, o generar una obra derivada a partir de esta obra. \\
$\underline{\text { Resumen de licencia }-\underline{\text { Texto completo de la licencia }}}$ \\
\end{tabular}


